\title{
Role Of Leadership In Building A Sense Of Community: A Preliminary Investigation
}

Pooja Mehta and Venkat R. Krishnan*

\begin{abstract}
An attempt is made in this preliminary study to measure the sense of community among employees, and to look at its relationship with the perceived leadership style of the supervisor. The results indicate that nurturant, task-oriented, and participative styles of leadership are positively related to a sense of community among employees.
\end{abstract}

Organizations are realizing the importance of the concept of a community. This shows that organizations realize the importance of meaningful relationships among employees at the work place (Hanson, . 1996). Employees' relationships with other employees make more difference to the production and morale than was believed earlier. Two important reasons to study relationships at work are to create a. supportive environment for the employees and to create a balanced and adaptive organization (Kofodimos, 1993). However, building this community involves a lot of risk for the prevailing leadership as it means letting go of their hold to a certain degree. This paper is an attempt to study the relationships between various styles of leadership of the superior and the feeling of community among the employees.

\section{What is a Community?}

Community could be defined as a collection of people within a geographic area among whom there is some degree of mutual identification, interdependence or organized activity (Eshleman, 1993). In communities, individuals develop a sense of belonging. Values are generated and regenerated.

Pooja Mehta is Asst Manager at Avco Financial Services and Venkat R. Krishnan is an Associate Professor of Organizational Behavior at XLRI, Jamshedpur. Correspondence regarding this article may please be sent to Venkat $R$. Krishnan (e-mail: rkvenkat@geocities.com).
If leaders cannot find in their constituencies any base of shared values, principled leadership becomes nearly impossible. From social coherence, leaders expect of constituents or followers a great deal of participation and sharing of leadership tasks. If a community is healthy and coherent, it imparts a coherent value system and holds individuals within a framework of values. A traditional community is relatively homogenous, shows little change, demands a high degree of conformity, does not welcome strangers, is all too ready to reduce its communication with the external world, is typically small and can boast of continuity (Gardner, 1990).

Community is characterized by five factors-envisioning, unity, empowering, exploring, and reflecting - that depend on the perception of the community members (Tjosvold, 1991). Envisioning is the feeling of moving in a clear and engaging direction. This includes reflection on the organization's framework, grievance resolution, opportunities for change, innovation and growth, taking risks and learning from mistakes, good communication of the vision statement and appreciation of accomplishments. Unity lies in believing in the value of the vision provided by the leader. It also includes assigning of responsibilities to different members to coordinate different aspects of solutions, keeping track of the individual's performance, and promoting 
group learning. This includes sharing of information, praising the whole team for success, rewarding individuals based on group performance, making the task challenging, promoting personal relationships, encouraging team identity and assigning complementary roles. Empowering includes allocation of resources, inclusion of skilled, relevant people, developing abilities, structuring opportunities to work together and holding individuals accountable. Exploring includes establishing openness norms, recognizing opposing views, including diverse people, emphasizing common ground, combining ideas and consulting relevant resources. Reflecting includes analyzing the data collected, structuring time to discuss the findings, stressing understanding of others' perspectives, defining issues specifically, recognizing the gains of resolving conflicts, flexibility in ways to develop useful solutions and striving for improvement.

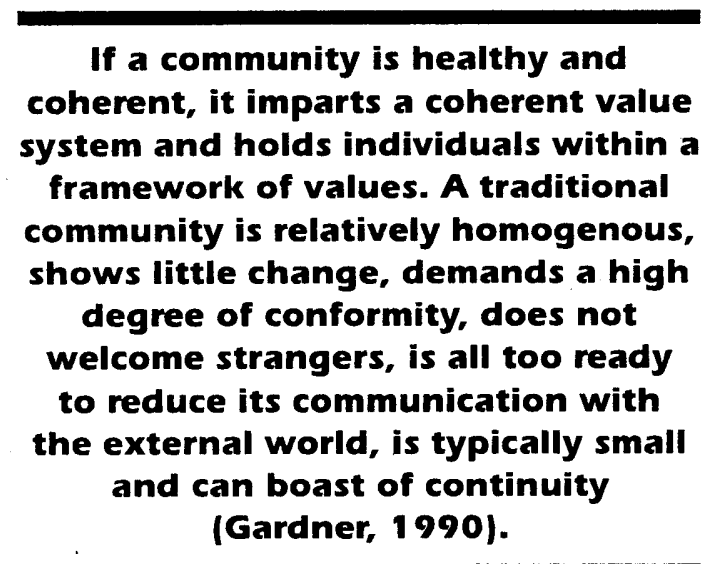

According to Gardner (1990), some ingredients of a community are:

1. Wholeness incorporating diversity: vital communities face and resolve differences.

2. Shared culture: shared norms and values are present. The community has symbols of group identity. Social cohesion is advanced if norms and values are explicit. It provides opportunities to express values in relevant action, affirms itself, and builds morale through ceremonies that honour symbols of shared identity.

3. Good internal communication: members should communicate freely. Leaders have to combat "we-they"' barriers that impede the free flow of communication within their membership.

4. Caring, trust and teamwork: the feelings that the members of a community usually experience, when they are put in a situation together, are that they are cared for, they can trust each other and they are a team.

5. Group maintenance and government: a community has institutional provisions for group maintenance or governing.

6. Participation and sharing of leadership tasks: a healthy community encourages individual involvement in the pursuit of shared purposes.

7. Development of young people: new people who are inducted are groomed to fit into the community.

8. Links with the outside world: every community needs to have fruitful links with the larger communities of which it is a part.

\section{Leadership}

Researchers usually define leadership according to their individual perspectives and the aspects of the phenomenon which are of most interest to them. Hemphill and Coons (1957) have defined leadership as the behavior of an individual when he is directing the activities of a group toward a shared goal. Burns (1978) defined leadership as inducing followers to pursue common or at least joint purposes that represent the values and motivations of both leaders and followers. Jacobs and Jaques (1990) have defined leadership as a process of giving meaningful purpose to collective effort, and causing willing effort to be expended to achieve a 
purpose. Leadership is generally considered as a process of influencing the activities of a group in an effort to achieve certain organizational goals (Hingar, 1986). Yukl (1998) defines leadership as interpersonal influence, exercised in a situation, and directed, through the communication process, towards the attainment of a specified goal or goals. In keeping with the view of the organization as a community, it is quite clear that interpersonal styles and interactional patterns become important. Thus, leadership can be taken as a function of the dynamic interrelationship of the expectations of subordinates, the personality characteristics of superiors and the demands of the situation (Verma, 1986).

\section{Thus, leadership can be taken as a function of the dynamic interrelationship of the expectations of subordinates, the personality characteristics of superiors and the demands of the situation (Verma, 19861.}

Leadership styles can be classified into five categories (Sinha, 1995; Verma, 1986):

1. The Bureaucratic Style : Bureaucracy illustrates characteristics like specialization of labour, well-defined hierarchy of authority, clearly laid down responsibilities, systems of rules and procedures, impersonality of relations, promotions based on technical qualifications and centralization of authority.

2. The Nurturant Style : Nurturant leaders care for their subordinates, show affection, take personal interest in subordinates' well-being and are committed to their growth. The nurturant style has been identified as the preferred style for a superior in India (Sinha, 1997).

3. The Task-Oriented Style : Task-oriented leaders emphasize task performance. They are controlling and assertive, drive their subordinates hard towards organizational goals.

4. The Authoritarian Style: This kind of style has the characteristics of rigidity, selfcenteredness, suspicion, insecurity and anxiety. The behavioural manifestations are excessive dependency of subordinates, strict control of subordinates and stereotyping. The emphasis is on strict observance of discipline.

5. The Participative Style : Participative leaders are democratic, considerate, permissive and non-directive. They share their decision-making and understand their subordinates' feelings.

The personal warmth of nurturant leaders creates a climate of trust and understanding where subordinates grow and acquire maturity. Due to an emphasis on task performance by task-oriented leaders, the organizational productivity will increase and a congenial work atmosphere will be established. In the case of participative leadership, mutual trust develops and high motivation and willingness to assume responsibilities become evident and free interaction is observed. Therefore, we hypothesize:

\section{Hypothesis 1: A nurturant, task- oriented and participative leadership of the manager will be positively correlated to the sense of community among members of the work unit.}

The behaviour of bureaucratic leaders will be impersonal and barely acceptable, as they tend to become more mechanical. In the case of authoritarian leadership, the subordinate becomes dependent and submissive and a fear of being punished is always present (Verma, 1986). Hence, we hypothesize: 


\section{Hypothesis 2: A bureaucratic and authoritarian leadership of the manager will be negatively correlated to the sense of community among members of the work unit.}

\section{Methodology}

We used the 43-item Leadership Style Scale (Verma, 1986) to measure authoritarian ( 9 items), participative ( 8 items), task-oriented (10 items), nurturant ( 8 items) and bureaucratic ( 8 items) leadership styles. This scale has been found reliable and has been used in a number of studies and with different samples such as university heads, service organizations, production units, public sector, private sector, bureaucrats and mostly on executives of work organizations. The superior's leadership style was measured by getting the subordinate's responses to the questionnaire. The responses were taken on a 5 -point scale $(1=$ false; $2=$ partly false; $3=$ undecided; $4=$ partly true; $5=$ true).

To measure the sense of community, we used Gardner's (1990) framework that groups the ingredients of community along eight dimensions. We generated 22 items to capture the eight dimensions. A 5-point scale $(1=$ to a very small extent; $2=$ to a small extent; $3=$ undecided; $4=$ to a great extent; $5=$ to a very great extent) was used to record the responses. We did a pilot survey to test the scale using a sample of 22 full time graduate business students. Responses were collected on the 22 items using the 5-point scale, and in addition, we interviewed the respondents to obtain a direct score on each of the eight dimensions. The correlation between the questionnaire scores and the interview scores was 0.53 ( $p<$ 0.05). We dropped two items from the scale to enhance its reliability. The Cronbach alpha for the remaining 20 items (only these 20 items were subsequently used in this study) was 0.72 . The list of the final 20 items comprising the community scale is included in the appendix.
The study was conducted in a steel manufacturing company in eastern India. The company started as a family owned business but over the years has introduced professional management. The sample consisted of 50 senior executives at the levels of assistant general manager, deputy general manager, general manager and senior general manager. The executives answered questionnaires that measured the leadership styles of their superiors and the sense of community in their work unit.

\section{Results}

The Cronbach alpha was less than 0.3 in the case of three of the eight community dimensions:- wholeness incorporating diversity (0.08), group maintenance and government (0.07), and development of young people (0.26). Hence these three dimensions were excluded from the study because of low scale reliability. Correlations between the remaining five community dimensions and the five leadership styles are presented in the table.

The results indicate that the nurturant style of leadership is significantly positively correlated to three of the five community dimensions:- shared culture, good internal communication, and participation and sharing of leadership. The task-oriented style is also significantly positively correlated to three of the five community dimensions:shared culture, caring, trust and teamwork, and participation and sharing of leadership. The participative style is significantly positively correlated only to the shared culture dimension of community. Thus, hypothesis 1 is partially supported. From the table, it is clear that the bureaucratic style is significantly negatively correlated only to one of the five community dimensions:- links with the outside world. The authoritarian style is not found to be significantly correlated to any of the dimensions of community. Hypothesis 2 is thus supported only in the case of one community dimension (links with 
the outside world) and one leadership style (bureaucratic).

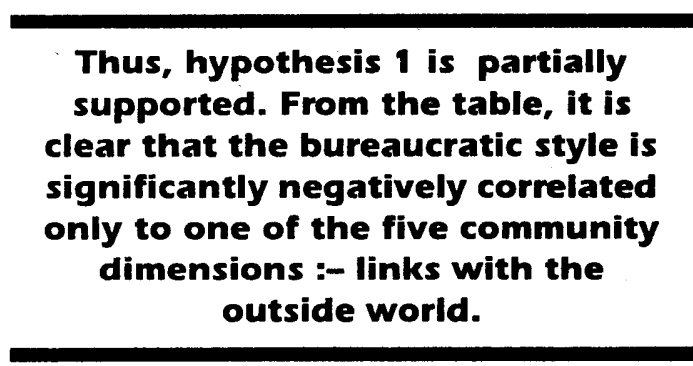

A certain pattern can be seen in the correlations between the variables studied. Although the hypotheses of the study are only partly supported, it can be seen that at least one of the four community dimensions of shared culture, good internal communication, caring, trust and teamwork, and participation and sharing of leadership is positively related to the nurturant, task-oriented and participative leadership styles. Analyzing the correlations between the leadership styles, it can be seen that there is a significant positive correlation ( $r=0.65$ and above) between the nurturant, task-oriented and participative styles of leadership.

This explains the finding that four community dimensions are related to these three leadership styles-nurturant. It is logical to expect in the light of such findings that these three styles of leadership will promote a strong sense of community in the organization. It is also to be noted that the four community dimensions of shared culture, good internal communication, caring, trust and teamwork, and participation and sharing of leadership are significantly related to each other.

The bureaucratic style is negatively related to the community dimension of links with the outside world, which indicates that this style of leadership is more inward-looking or more rigid in its response to the outside world. Such a style, when prevalent in an organization, would result in compartmentalization of various departments and isolation of the organization from the external environment. There will be little awareness of other aspects of the organization which will hinder the sense of community within the organization. The authoritarian style was not found to be significantly correlated to any of the dimensions of the sense of community. This can be interpreted to mean that the authoritarian style is not conducive to a sense of community. The findings also indicate that the bureaucratic style is negatively correlated to the participative style; while the authoritarian style is negatively correlated to the nurturant and participative styles.

The authoritarian style was not
found to be significantly correlated
to any of the dimensions of the sense
of community. This can be
interpreted to mean that the
authoritarian style is not conducive
to a sense of community.

Conclusion

A greater sense of community among employees leads to a greater identification with the organization, good working relationships, increased productivity and job satisfaction. However, a sense of community may also be a hindrance sometimes. With changes in the business scenario of organizations, it is required that organizations should be able to adapt quickly to the changes. Organizational change requires frame breaking, an ability to think differently from the prevalent thinking. Now a community thrives because its members follow norms and traditions that have already been set. It creates a "we-they" barrier between itself and the outside world and demands a high degree of conformity. These conditions imply a certain rigidity which may not be conducive to situations requiring quick change though the positive aspects of a sense of community cannot be denied. Future research needs to look at a possible optimum level of the sense of community beyond which it becomes 
counter-productive. The scales that we developed for measuring the sense of community can also be further refined and tested on a wider sample.

\section{REFERENCES}

1. Burns, J.M. 1978. Leadership. New York: Harper \& Row.

2. Eshleman, R.J. 1993. Sociology: An introduction. New York: Harper-Collins.

3. Gardner, J.W. 1990. On leadership. New York: Free Press.

4. Hanson, D. 1996. Building community. Executive Excellence, June: 5.

5. Hemphill, J.K., \& Coons, A.E. 1957. Development of the leader behavior description questionnaire. In R.M. Stogdill \& A.E. Coons (eds.), Leader behavior: Its description and measurement. Columbus, Ohio: Bureau of Business Research, Ohio State University.

6. Hingar, A. 1986. Leadership styles and job satisfaction. New Delhi: Printwell Publishers.
7. Jacobs, T.O., \& Jacques, E. 1990. Measures of leadership. West Orange, NJ: Leadership Library of America.

8. Kofodimos, J. 1993. Balancing act. San Francisco: Jossey-Bass.

9. Sinha, J.B.P. 1995. The cultural context of leadership and power. New Delhi: Sage.

10. Sinha, J.B.P. 1997. A cultural perspective on organizational behavior in India. In P.C. Earley \& M. Erez (Eds.), New perspectives on international industrial/ organizational psychology 53-74. San Francisco: The New Lexington Press.

11. Tjosvold, D.W. 1991. Leading the team organization. New York: Lexington.

12. Verma, N. 1986. Leadership styles in interpersonal perspective. Delhi: B.R. Publishing.

13. Yukl, G. 1998. Leadership in Organizations, Englewood Cliffs, NJ: Prentice Hall.

Table : Correlations among Variables Studied

\begin{tabular}{lllllllllllll}
\hline$(\mathrm{N}=50)$ & Mean & $\mathrm{SD}$ & 1 & 2 & 3 & 4 & 5 & 6 & 7 & 8 & 9 & 10 \\
\hline
\end{tabular}

COMMUNITY

1. Shared Culture $\quad 3.15 \quad 1.13 \quad(0.67)$

2. Good Internal Communication $3.10 \quad 1.20 \quad * 0.43 \quad(0.68)$

3. Caring, Trust and Teamwork $\quad 2.90 \quad 1.20 \quad * 0.64 \quad{ }^{*} 0.56 \quad(0.68)$

4. Participation and Sharing of Leadership

$\begin{array}{llllll}3.00 & 1.20 & * 0.41 & * 0.59 * 0.57 \quad(0.51)\end{array}$

$\begin{array}{llllllll}\text { 5. Links With Outside World } & 2.70 & 1.20 & 0.09 & * 0.39 & 0.17 & * 0.47 & (0.63)\end{array}$

\section{LEADERSHIP}

\begin{tabular}{|c|c|c|c|c|c|c|c|c|c|c|c|}
\hline 6. Bureaucratic & 3.30 & 1.10 & 0.19 & 0.06 & 0.15 & -0.13 & $*-0.33$ & $(0.07)$ & & & \\
\hline 7. Nurturant & 3.50 & 1.10 & ${ }^{*} 0.33$ & $* 0.28$ & 0.24 & ${ }^{*} 0.36$ & 0.07 & -0.10 & $(0.79)$ & & \\
\hline 8. Task-oriented & 4.00 & 0.09 & ${ }^{*} 0.46$ & 0.22 & ${ }^{*} 0.33$ & ${ }^{*} 0.40$ & 0.01 & -0.10 & ${ }^{*} 0.65$ & $(0.83)$ & \\
\hline 9. Authoritarian & 3.20 & 1.20 & 0.14 & -0.10 & 0.02 & -0.20 & -0.20 & 0.27 & $*-0.38$ & -0.10 & $(0.76)$ \\
\hline 10. Participative & 3.60 & 1.00 & ${ }^{*} 0.48$ & 0.18 & 0.18 & 0.26 & 0.11 & ${ }^{*}-0.30$ & $* 0.69$ & ${ }^{*} 0.71$ & ${ }^{*}-0.42(0.84)$ \\
\hline
\end{tabular}

$*=\mathrm{p}<0.05$.

Cronbach alphas are in parentheses along diagonal. 


\section{APPENDIX}

\section{Community Scale Items}

\section{Wholeness incorporating diversity}

1. To what extent do you feel that people from the same backgrounds (city, religion, work category) stick together in your work situation?

2. Do you feel that often there are arguments or differences of opinion in your work situation which are promptly resolved?

\section{Shared culture}

3. Do you feel that there is a set of norms in your work situation which are followed by all (from top to bottom)?

4. Do you feel there is a strong sense of "group identity" in your work situation?

5. To what extent do you feel that people in your work situation are committed to the departmental goals?

\section{Good internal communication}

6. To what extent are you satisfied with the formal/informal forums provided to voice your opinions to the higher management?

7. To what extent do you feel free to discuss your problems with other people in your work situation (superiors, co-workers)?

8. To what extent do you feel that there are ample opportunities (social get-togethers, meetings etc...) for the members of your department to meet each other?

\section{Caring, trust and teamwork}

9. To what extent do you feel that people in your work environment act with integrity?

10. Do you feel that your work environment stresses group work more rather than individual work?
11. To what extent do you think that your work environment is receptive to new ideas?

\section{Group maintenance and government}

12. Do you feel that most decisions aire made by the top management without consulting the lower management?

13. To what extent do you feel that the reporting structure in your work environment is very rigid?

\section{Participation and sharing of leadership}

14. To what extent do you feel that your work environment implements the feedback of its people?

15. To what extent do you feel free to express your opinions in a group situation?

16. To what extent do you feel that information about employees or the company is shared with the employees?

\section{Development of young people}

17. Do you feel that there is a comprehensive induction and recruitment programme for new employees to orient them to the organisation's objectives and culture?

18. Do you feel there are enough opportunities for people in your work environment to exhibit their leadership skills?

\section{Links with the outside world}

19. Do you feel that the in-house publications have contributed to your awareness of your own department?

20. To what extent do you feel that people in your department are aware of the oals / challenges in other departments of the organization? 